\title{
Laboratory Test Time Point
}

National Cancer Institute

\section{Source}

National Cancer Institute. Laboratory Test Time Point. NCI Thesaurus. Code C83158.

A point in time that the laboratory test takes place. 